\title{
Mechanical Properties and Microstructure of AZ31B Magnesium Alloy Processed by I-ECAP
}

\author{
MICHAL GZYL, ANDRZEJ ROSOCHOWSKI, RAPHAEL PESCI, LECH OLEJNIK, \\ EVGENIA YAKUSHINA, and PAUL WOOD
}

\begin{abstract}
Incremental equal channel angular pressing (I-ECAP) is a severe plastic deformation process used to refine grain size of metals, which allows processing very long billets. As described in the current article, an AZ31B magnesium alloy was processed for the first time by three different routes of I-ECAP, namely, $\mathrm{A}, \mathrm{B}_{\mathrm{C}}$, and $\mathrm{C}$, at $523 \mathrm{~K}\left(250{ }^{\circ} \mathrm{C}\right)$. The structure of the material was homogenized and refined to $\sim 5$ microns of the average grain size, irrespective of the route used. Mechanical properties of the I-ECAPed samples in tension and compression were investigated. Strong influence of the processing route on yield and fracture behavior of the material was established. It was found that texture controls the mechanical properties of AZ31B magnesium alloy subjected to I-ECAP. SEM and OM techniques were used to obtain microstructural images of the I-ECAPed samples subjected to tension and compression. Increased ductility after I-ECAP was attributed to twinning suppression and facilitation of slip on basal plane. Shear bands were revealed in the samples processed by I-ECAP and subjected to tension. Tensioncompression yield stress asymmetry in the samples tested along extrusion direction was suppressed in the material processed by routes $B_{C}$ and $C$. This effect was attributed to textural development and microstructural homogenization. Twinning activities in fine- and coarsegrained samples have also been studied.
\end{abstract}

DOI: $10.1007 / \mathrm{s} 11661-013-2094-\mathrm{z}$

(C) The Minerals, Metals \& Materials Society and ASM International 2013

\section{INTRODUCTION}

MAGNESIUM alloys are metallic materials that can be used for lightweight, energy-saving structures, and medical devices. Unfortunately, their low formabilities at room temperature make their practical usage very challenging. Many thermomechanical processes were developed to enhance ductility of magnesium alloys. The most promising method that can improve their strengths and formabilities is severe plastic deformation (SPD). ${ }^{[1]}$ In SPD processes, a large plastic strain is imposed to material (without changing its dimensions) to refine its microstructure. SPD is commonly used to convert coarse-grained metallic materials into ultrafine-grained (UFG) materials with the average grain size less than 1 micrometer.

Equal channel angular pressing (ECAP) is one of the most developed SPD processes. ${ }^{[2]}$ In ECAP, a billet is pressed through a die with two channels; the

MICHAL GZYL, Research Assistant, EVGENIA YAKUSHINA, Research Fellow, and PAUL WOOD, Senior Research Fellow, are with the Advanced Forming Research Centre, University of Strathclyde, 85 Inchinnan Drive, Renfrew PA4 9LJ, U.K. Contact e-mail: michal.gzyl@gmail.com ANDRZEJ ROSOCHOWSKI, Reader, is with the Design, Manufacture and Engineering Management, University of Strathclyde, James Weir Building, 75 Montrose Street, Glasgow G1 1XJ, U.K. RAPHAEL PESCI, Assistant Professor, is with the ENSAM-Arts et Métiers ParisTech, Laboratory LEM3, UMR CNRS 7239, 4 rue Augustin Fresnel, 57078 Metz, France. LECH OLEJNIK, Senior Lecturer, is with the Institute of Manufacturing Technologies, Faculty of Production Engineering, Warsaw University of Technology, 85 Narbutta St., 02-524 Warsaw, Poland. Manuscript submitted August 21, 2013.

Article published online November 7, 2013 deformation zone is localized at channels' intersection; and deformation mechanism is simple shear. The amount of plastic strain imposed to material depends on the channel intersection angle and its outer curvature; it can be calculated theoretically. ${ }^{[3]}$ Due to frictionrelated force limitation, only relatively short billets can be processed using this method. The solution of the problem can be incremental ECAP (I-ECAP) developed by Rosochowski and Olejnik ${ }^{[4]}$ In I-ECAP, a force needed to conduct the process is reduced significantly because of separation of material feeding and deformation. This method can be used to produce UFG rods, plates $^{[5]}$ and sheets. ${ }^{[6]}$

Due to low formability of magnesium alloys at room temperature, ECAP must be realized at elevated temperatures. A typical processing temperature varies from $448 \mathrm{~K}$ to $523 \mathrm{~K}\left(175{ }^{\circ} \mathrm{C}\right.$ to $\left.250{ }^{\circ} \mathrm{C}\right)$; the lower the temperature the smaller the grain size obtained. The mean grain sizes reported for different conditions were $1 \mu \mathrm{m}$ at $423 \mathrm{~K}\left(150{ }^{\circ} \mathrm{C}\right),{ }^{[7]} 2 \mu \mathrm{m}^{[8,9]}$ at $473 \mathrm{~K}\left(20{ }^{\circ} \mathrm{C}\right)$, and $6 \mu \mathrm{m}$ at $523 \mathrm{~K}\left(250^{\circ} \mathrm{C}\right) \cdot{ }^{[10,11]} \mathrm{In}$ order to enable further grain refinement, the processing temperature must be decreased along with a simultaneous decrease of strain rate. Different experimental plans were proposed to conduct ECAP at temperatures lower than $473 \mathrm{~K}$ $\left(200{ }^{\circ} \mathrm{C}\right)$ without crack occurrence. They are based on the idea of gradual temperature decrease with subsequent passes. ${ }^{[12-14]}$ The smallest reported grain size obtained using this method was equal to $0.37 \mu \mathrm{m}$ at the final temperature $388 \mathrm{~K}\left(115^{\circ} \mathrm{C}\right) .^{[13]}$

The grain-refinement mechanism during the processing of magnesium alloys by ECAP is significantly 
different from that for fcc metals. ${ }^{[15]}$ According to a model proposed by Figueiredo and Langdon ${ }^{[16]}$ and experimental results, ${ }^{[8,9,17,18]}$ the grain-refinement process is controlled by dynamic recrystallization (DRX). Observations of necklace-like and bimodal microstructures after ECAP of initially coarse-grained materials have confirmed this hypothesis. A critical grain size term was introduced in this model to account for a complete microstructural homogenization. ${ }^{[16]}$ The occurrence of DRX also explains why grains with only limited size can be obtained at a given temperature. The studies on DRX in AZ31 magnesium alloy during compression testing show that the size of recrystallized grains is dependent on temperature and strain. However, relation between inverse grain size and strain is not linear, and after reaching a maximum point, the size of recrystallized grains remains constant despite further deformation. ${ }^{[19,20]}$ Similarly in ECAP, after reaching a minimum mean grain size for a given temperature, subsequent passes do not lead to further grain refinement but only to microstructural homogenization. The multiscale cellular automata finite element (CAFE) model of microstructural evolution during ECAP of magnesium alloys based on DRX approach was developed by the authors of this article, and the numerical results were found to be in good agreement with experiments. ${ }^{[21]}$

In contrast to fcc metals, the yield stress of magnesium alloys is usually decreased by ECAP processing. The inverse Hall-Patch effect, a negative slope of yield stress versus inverse mean grain size, was reported for ECAPed AZ61. ${ }^{[17]}$ The decrease of the yield strength with subsequent passes of ECAP was also shown in other articles. ${ }^{[10,22]}$ On the other hand, increase of yield stress after four passes was reported in Reference 18. Significant improvement in the strength of AZ31 magnesium alloy (0.2 pet proof strength equal to $372 \mathrm{MPa})$ was reported only for grain sizes smaller than $1 \mu \mathrm{m} .{ }^{[13]}$ Mukai et al. ${ }^{[23]}$ reported similar properties (yield stress $\sim 400 \mathrm{MPa}$ ) for the mean grain size $1.5 \mu \mathrm{m}$ after multidirectional rolling. Ductility of magnesium alloys is usually enhanced by ECAP. Maximum elongation can exceed 40 pct after ECAP and subsequent annealing. ${ }^{[24,25]}$

A strong texture is produced in magnesium alloys processed by ECAP. ${ }^{[13,26]}$ Mukai et al. ${ }^{[24}$ suggested that majority of grains change their orientation in a way such that their basal planes are coincident with a shear plane. This observation was later confirmed by textural measurements. ${ }^{[25]}$ Textural development is believed to be responsible for the decrease of yield stress and enhancement of ductility in ECAPed $\mathrm{Mg}$ alloys despite the significant grain refinement. Nevertheless, Mukai et $a{ }^{\left[{ }^{[24]}\right.}$ also showed that ECAP followed by annealing can remarkably improve room temperature ductility of AZ31 magnesium alloy. The mean grain size obtained measured about $1 \mu \mathrm{m}$ after ECAP and $15 \mu \mathrm{m}$ after subsequent annealing. Agnew et al. ${ }^{[25]}$ reported that annealing had not changed the texture developed during ECAP. Therefore, enhancement of ductility was explained by recrystallization effects and grain growth during heat treatment.
The ECAP process can be realized using different processing routes. ${ }^{[15]}$ Route A means that a billet is not rotated between subsequent passes of I-ECAP, routes $\mathrm{B}_{\mathrm{C}}$ and $\mathrm{C}$ indicate rotation by 90 and $180 \mathrm{deg}$, respectively. Experiments showed strong dependence between an ECAP route and generated texture. ${ }^{[13,26,27]}$ After processing by routes $\mathrm{B}_{\mathrm{C}}$ and $\mathrm{C}$, basal planes are inclined at nearly $45 \mathrm{deg}$ to extrusion direction (ED). However, for route A basal planes remain nearly parallel to ED. In Reference 13, higher strength obtained after processing by route $\mathrm{A}$ was attributed to textural development since the measured grain sizes were almost equal for different routes $(1.8 \pm 0.1 \mu \mathrm{m})$. The results presented suggest that mechanical properties of magnesium alloys are dependent on the combination of grain size and texture.

The most favorable deformation mechanism occurring in magnesium alloys at room temperature is slip on basal plane. Critical resolved shear stresses (CRSS) for pyramidal and prismatic slip are much higher so that their contribution to plastic deformation at room temperature is small. ${ }^{[28-31]}$ Activation of basal slip is dependent on grain orientation. Experiments ${ }^{[32]}$ and theoretical calculations ${ }^{[33]}$ showed that Schmid factor for basal slip is increased when basal planes are inclined by $\sim 45 \mathrm{deg}$ to deformation direction. Since only two independent slip systems can operate on basal plane, twinning is necessary to accommodate plastic strain and fulfill von Mises criterion. ${ }^{[34]}$ Moreover, slip on basal plane is impossible if the $c$-axis of the crystallographic cell is aligned exactly parallel to tension/compression direction. In this case, twinning or nonbasal slip needs to be activated to accommodate plastic deformation. It was shown that twinning activity is dependent on grain size, and it is more likely to occur in coarse rather than fine grains. $^{[35]}$

A comprehensive study on grain size influence on compressive deformation of AZ31 magnesium alloy has been conducted by Barnett et al. ${ }^{[36]}$ The flow stress curves were obtained for hot-extruded AZ31 with grain sizes varying from 3 to $22 \mu \mathrm{m}$ at the temperatures ranging from ambient to $473 \mathrm{~K}\left(200{ }^{\circ} \mathrm{C}\right)$. A distinctive concave shape of flow stress curve, typical for twinning-dominated deformation, was reported at room temperature even for grains as small as $3 \mu \mathrm{m}$. Transition from twinning to slipdominated deformation was presented as a function of temperature and grain size. It was concluded that twinning in compression can be avoided in fine-grained AZ31 by temperature increase up to $423 \mathrm{~K}\left(150{ }^{\circ} \mathrm{C}\right)$. However, recent reports ${ }^{[37,38]}$ show that ECAP processing can lead to twinning suppression during compression along ED at room temperature. Therefore, a textural effect should also be taken into account when investigating twinning behavior of magnesium alloys.

In the current article, the effects of processing route of I-ECAP on mechanical properties, grain size, and texture of an AZ31B magnesium alloy are investigated. Microstructural characterizations of the tensioned and compressed coarse- and fine-grained samples are performed to determine the dominating deformation mechanism. The tension-compression yield stress 
anisotropies of coarse- and fine-grained materials are also studied. Moreover, the influence of texture on the twinning activity in fine-grained samples obtained by different routes of I-ECAP and subjected to compression is shown.

\section{MATERIALS AND METHODS}

\section{A. Material}

Bars with square cross section $10 \times 10 \mathrm{~mm}^{2}$ and length equal to $120 \mathrm{~mm}$ were obtained from commercially extruded AZ31B rods (16 $\mathrm{mm}$ in diameter). As seen in Figure 1, the as-received microstructure was very heterogeneous with coarse grains $(\sim 83 \mu \mathrm{m})$ surrounded by colonies of small grains $(\sim 12 \mu \mathrm{m})$. Small grains were arranged in long strings aligned along ED, which were separated by coarse-grain regions. Occurrence of smallgrain colonies was attributed to DRX during hot extrusion. Twins were hardly observed in the as-received material.

\section{B. Experimental Procedure}

Initially, mechanical properties and microstructure of the as-received material were examined. Then, bars
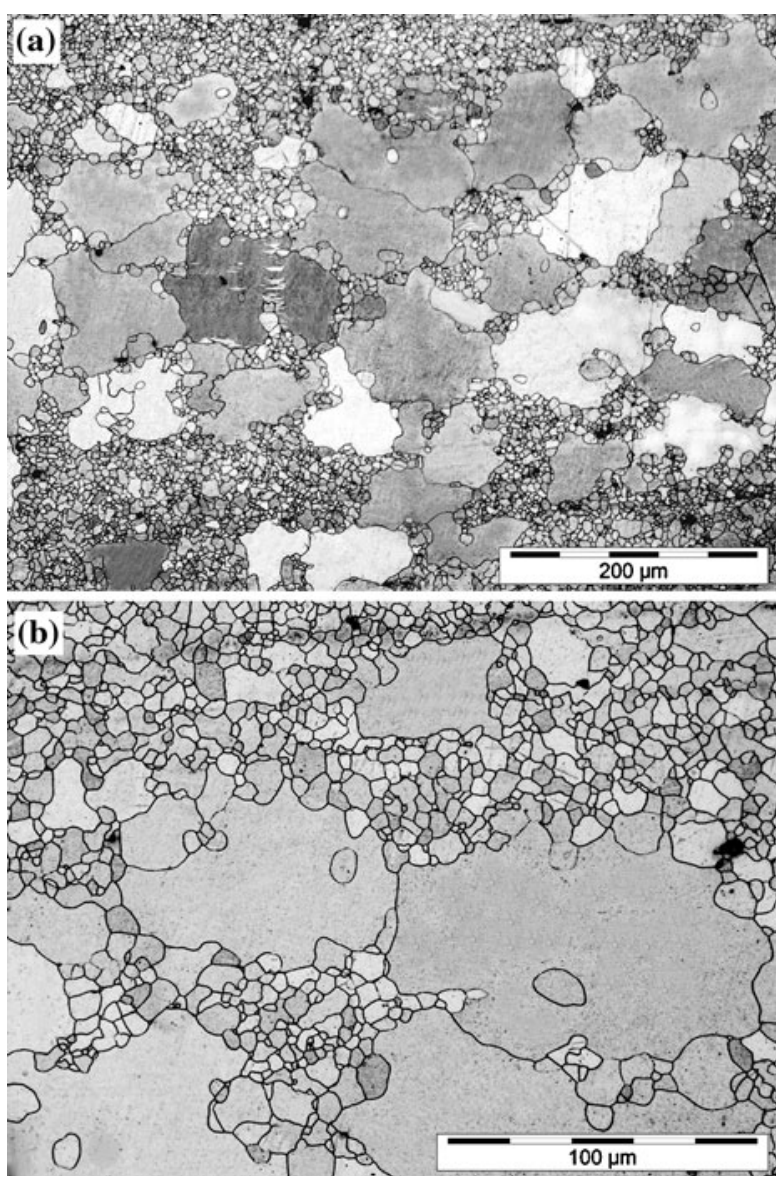

Fig. 1-Microstructure of the as-received, hot-extruded sample (AR) (a) and zoomed region showing coarse grains $(\sim 83 \mu \mathrm{m})$ surrounded by colonies of small grains $(\sim 12 \mu \mathrm{m})(b)$ machined from hot-extruded AZ31B were subjected to I-ECAP at $523 \mathrm{~K}\left(250^{\circ} \mathrm{C}\right)$ using different routes, namely $\mathrm{A}, \mathrm{B}_{\mathrm{C}}$, and $\mathrm{C}$. Images of fine-grained microstructures after 4 passes of I-ECAP were taken. Then, the samples machined from the processed material were subjected to tension and compression tests. Microstructural images were taken in the region of uniform deformation in the samples tested to fracture in tension. Compression tests were stopped after reaching true strain of $0.1 \pm 0.01$. Specimens for the microstructural characterization were cut out from the middle of the deformed cylinders. Samples with different processing histories are referred to in the text as AR-as-received hot-extruded; $\mathrm{A}$-processed by route A; B-processed by route $\mathrm{B}_{\mathrm{C}} ; \mathrm{C}$ - processed by route $\mathrm{C}$.

\section{Details of I-ECAP}

A double-billet variant of I-ECAP, with 90 deg angle between channels, was realized using a $1 \mathrm{MN}$ hydraulic servo press. Schematic illustration of the process is shown in Figure 2. The billets were fed using a motor-driven screw jack action of which was synchronized with the reciprocating movement of the punch. The feeding stroke was equal to $0.2 \mathrm{~mm}$. The punch movement followed an externally generated sine waveform with frequency $0.5 \mathrm{~Hz}$ and peak-to-peak amplitude equal to $2 \mathrm{~mm}$.

Composite coating was applied on the billet surface before lubrication with conventional molybdenum disulfide $\left(\mathrm{MoS}_{2}\right)$. The process is classified as nonchromate conversion coating with precipitation of ceramic phase by sol-gel mechanism. ${ }^{[39]}$ Billet preparation procedure included: (1) surface cleaning; (2) pickling; (3) application of composite coating; and (4) lubrication with $\mathrm{MoS}_{2}$ grease. The composite coating layer improved the grease adhesion significantly.

Heating of billets was realized by holding them for 15 minutes before processing in the die preheated to $523 \mathrm{~K}\left(250^{\circ} \mathrm{C}\right)$. The die temperature during processing was kept constant within $\pm 2 \mathrm{~K}$, based on the readings obtained from a thermocouple located near the deformation zone. Each billet was subjected to four passes of I-ECAP with rotation about its axis adequate for a particular route.

\section{Mechanical Testing and Microstructural Characterization}

Mechanical properties of the as-received and I-ECAPed materials were investigated using an Instron

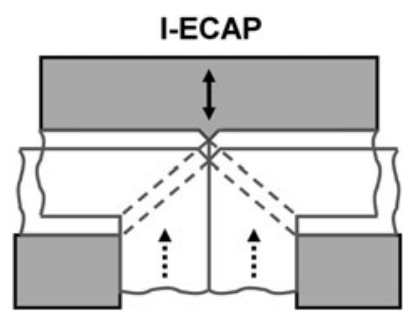

Fig. 2-Schematic illustration of I-ECAP. 
5969 testing machine with the maximum load capacity $50 \mathrm{kN}$. Tension and compression tests were carried out at room temperature with the initial strain rate equal to $1 \times 10^{-3} \mathrm{~s}^{-1}$. All specimens were cut out along ED. Flat tensile specimens, with thickness equal to $2 \mathrm{~mm}$ and dimensions of the gauge section $2.5 \mathrm{~mm} \times 14 \mathrm{~mm}$, were machined using wire electrical discharge machining. Height and diameter of the compression specimens were 8 and $7 \mathrm{~mm}$, respectively.

Microstructural characterizations were performed for the as-received rod, I-ECAPed bars, and tensile and compression specimens after testing. Samples from the as-received rod were cut out along ED. Billets after I-ECAP were characterized on planes perpendicular and parallel to ED. No significant difference in grain size between the two examined planes was observed. Tensile samples were analyzed on a plane parallel to the tested specimen's direction. Compressive specimens were examined on a plane perpendicular to compression direction. Samples were ground, polished, and etched after mechanical testing.

Olympus GX51 optical microscope and Quanta FEG 250 scanning electron microscope were used to perform microstructural characterization. Sample preparation procedure included grinding, polishing, and etching. Samples were ground using SiC paper P600 and P1200. Then, they were mechanically polished using polycrystalline suspensions with particle sizes: 9,3 , and $1 \mu \mathrm{m}$. Colloidal silica was used for final polishing. After polishing, specimens were etched using acetic picral to reveal twins and grain boundaries. Mean grain size was measured by a linear intercept method using Olympus analysis software. Representative images were chosen for grain size measurement; at least 500 grains were measured for each specimen.

The EBSD images of samples processed by different routes of I-ECAP were obtained using a Jeol 7001FLV scanning electron microscope equipped with a Nordlys II EBSD detector from Oxford Instruments. After grinding and polishing steps, samples were additionally chemically etched using nital 10 pet and polished with alumina $0.02 \mu \mathrm{m}$. The analyzed zones were about $400 \mu \mathrm{m} \times 270 \mu \mathrm{m}$ with a $0.2 \mu \mathrm{m}$ step size to be representative for the whole material; the indexation fraction was over 90 pet.

\section{RESULTS}

\section{A. Mechanical Properties}

Influence of I-ECAP processing route on mechanical behavior is shown in Figure 3. True tensile strain-stress curves are plotted in Figure 3(a). The strain at failure was increased from the initial value of 0.09 reported for hot-extruded rod, irrespective of the route used. However, enhancement of ductility for the sample A was less effective than for $\mathrm{B}$ and $\mathrm{C}$. Tensile strains at failure increased by 55,156 , and 155 pct for routes $A, B_{C}$, and $\mathrm{C}$, respectively. Processing by routes $\mathrm{B}_{\mathrm{C}}$ and $\mathrm{C}$ had the same effect on enhancement of ductility at room temperature. Using different processing routes had only

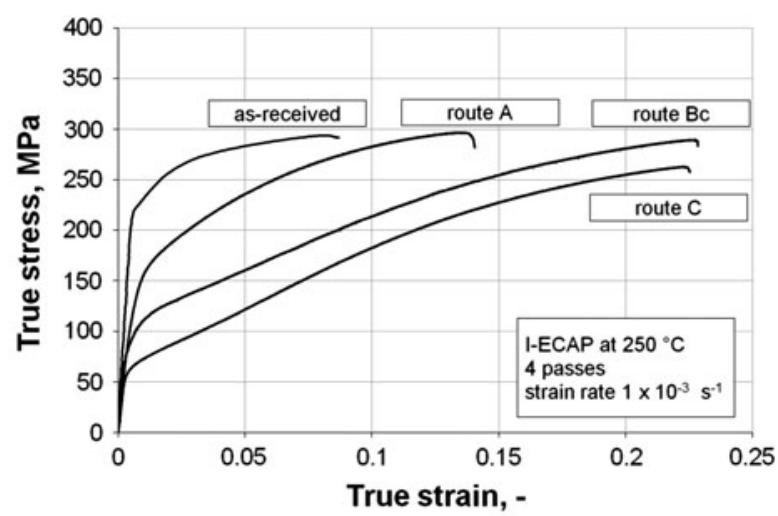

(a)

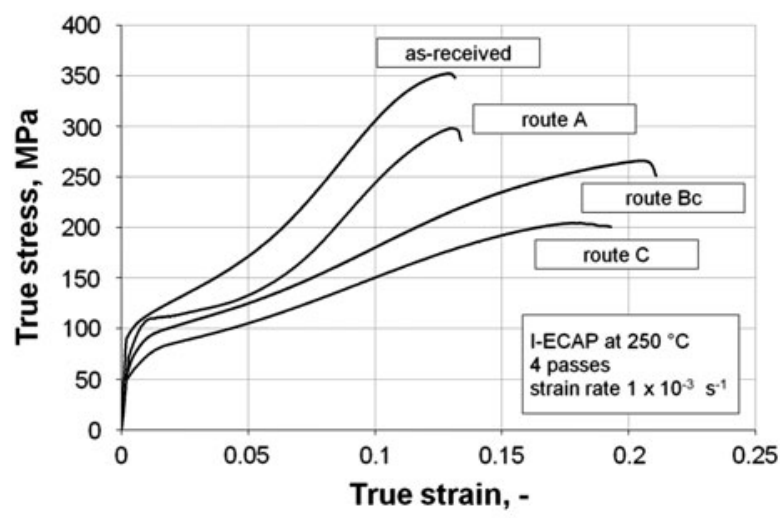

(b)

Fig. 3-Tensile $(a)$ and compressive $(b)$ true stress-strain curves for the as-received and I-ECAPed samples.

a limited effect on tensile strength of the material. True tensile strength was equal to $290 \pm 5 \mathrm{MPa}$ for the samples machined from the as-received rod and I-ECAPed billets processed by routes $A$ and $B_{C}$. However, tensile strength decreased to $262 \mathrm{MPa}$ for route C. Yield stress, defined as 0.2 pct offset proof stress, was decreased from initial 220 to $150 \mathrm{MPa}$ using route A. Increases in tensile ductility reported for the samples B and C came along with yield stress decreases to 95 and $60 \mathrm{MPa}$, respectively.

Results of room-temperature compression tests are shown in Figure 3(b). It is apparent from the presented plots that the shapes of the flow stress curves are strongly dependent on the processing route. Concave shape of the flow stress curve is observed for the extruded rod as well as the billet processed by route A. Yield stress and ductility of those samples are also very similar; however, only tensile strength is decreased by I-ECAP processing using route A. Similar to tensile tests results, yield stresses were decreased for routes $B_{C}$ and $C$ but the difference was within $50 \mathrm{MPa}$. Remarkable enhancement of ductility was reported for those routes, and compressive true strain at failure was increased from $\sim 0.13$ to $0.2 \pm 0.02$. Moreover, convex shape of flow stress curves and decreased strain hardening rate, in comparison with the samples AR and A, were observed for the samples B and C. 


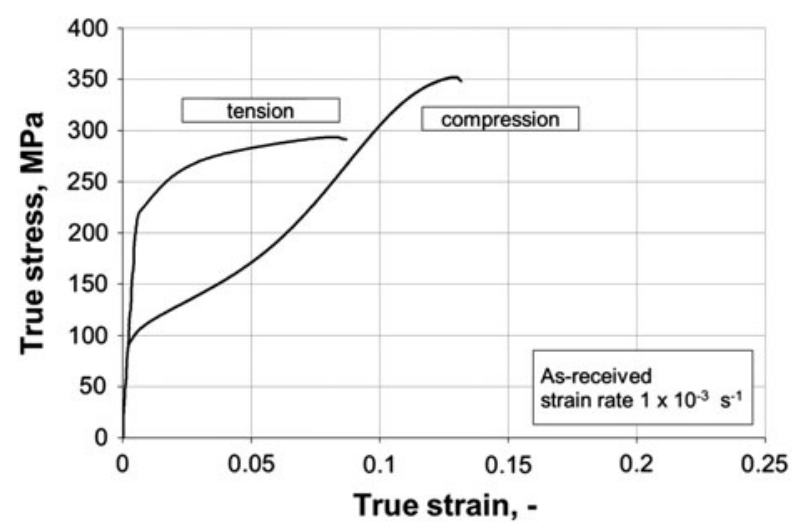

(a)

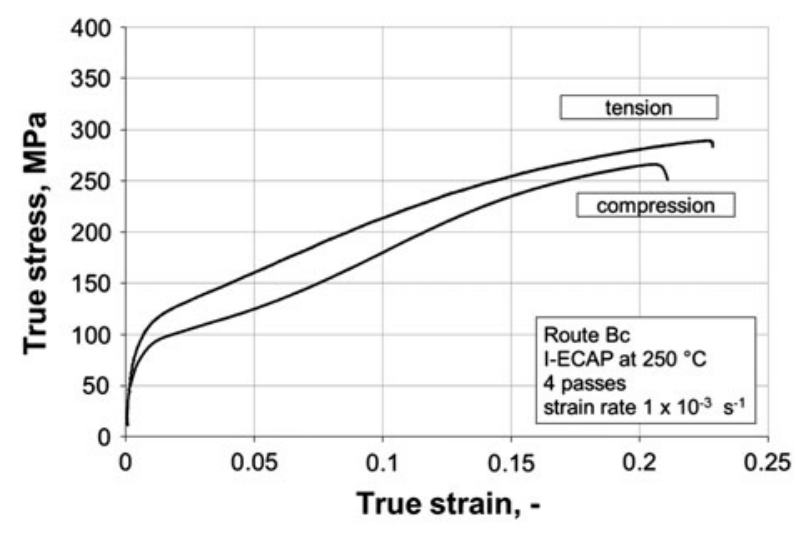

(c)

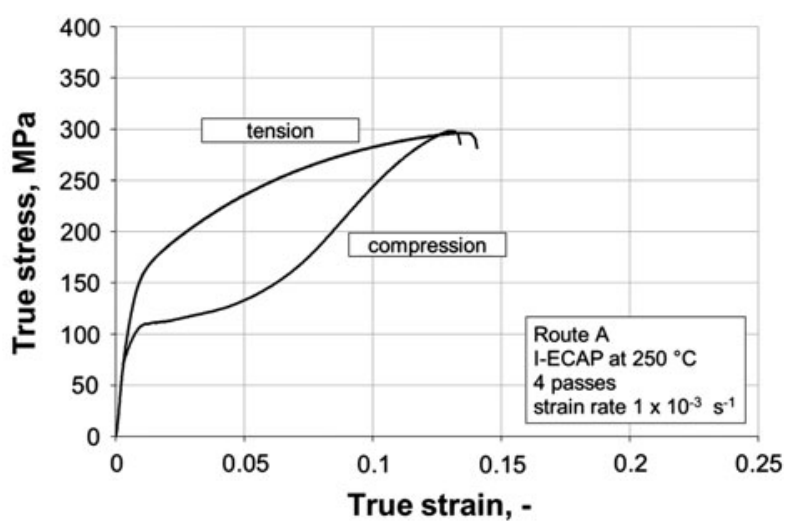

(b)

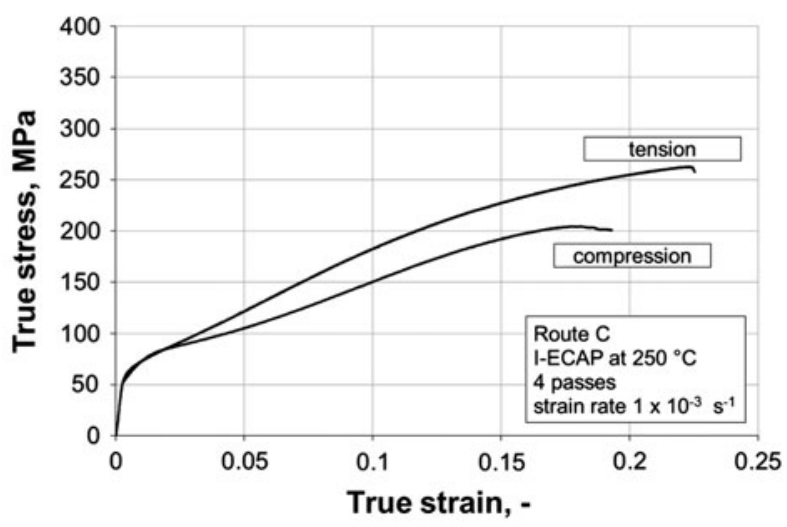

(d)

Fig. 4-True stress-strain curves showing tension-compression yield stress asymmetry of the as-received sample $(a)$ and the samples processed by different routes of I-ECAP: A $(b), \mathrm{B}_{\mathrm{C}}(c)$, and $\mathrm{C}(d)$.

Tension and compression flow stress curves for each processing route were plotted in Figure 4 to display tension-compression asymmetry. Yield stress asymmetry, $A_{\text {YS }}$, defined as a ratio of tensile yield stress to compressive yield stress was calculated for each sample. The largest asymmetry is reported for the sample AR, $A_{\mathrm{YS}}=2.25$. Yield stress asymmetry is decreased by I-ECAP to 1.5 and 1.25 for the samples $\mathrm{A}$ and $\mathrm{B}$, respectively. Processing by route $\mathrm{C}$ led to suppression of tension-compression yield stress anisotropy $\left(A_{\mathrm{YS}}=1.01\right)$. It is apparent from Figure 4 that flow behavior in tension is significantly different from that in compression for the samples AR and A. Higher strain hardening rates observed in compression tests could be attributed to the occurrence of $\{10-12\}$ tension twins. ${ }^{[40]}$ Strain hardening rate in compression decreased in the samples B and C, which makes their compressive flow behavior similar to the tensile one.

Tensile and compressive samples after testing are shown in Figure 5. The samples obtained from the as-received material and from a billet processed by route $\mathrm{C}$ of the I-ECAP (samples from billets processed by other routes behaved in a similar way) are displayed to compare different phenomena observed during the deformations of coarse- and fine-grained magnesium alloys. It is clear from Figures 5(a) and (b) that fracture mechanisms of the samples $\mathrm{AR}$ and $\mathrm{C}$ are different. Failure mechanism of the sample AR can be described as abrupt, very moderate ductile fracture (almost brittle) across a very short neck. The I-ECAPed samples exhibited uniform deformation without evident signs of necking. Moreover, each fine-grained sample fractured along shear plane coinciding with the orientation of I-ECAP shear plane. AR and C specimens compressed to strain 0.1 are shown in Figure 5(c). The compression flow behaviors of both the samples are quite different. Anisotropic flow observed for the sample $\mathrm{C}$ is not present in the sample AR. Material flow prevails in a direction perpendicular to ED; however, it is not clear if it is in transverse or normal direction. Ratio of the largest to the smallest radius, $A_{\mathrm{R}}$, was introduced as a measure of anisotropy. Anisotropic flow was not observed for the sample AR but $A_{\mathrm{R}}$ parameters were equal to $1.08,1.1$, and 1.13 for the samples A, B, and $\mathrm{C}$, respectively.

\section{B. Microstructure}

Remarkable homogenization and grain refinement were achieved after four passes of I-ECAP, irrespective 

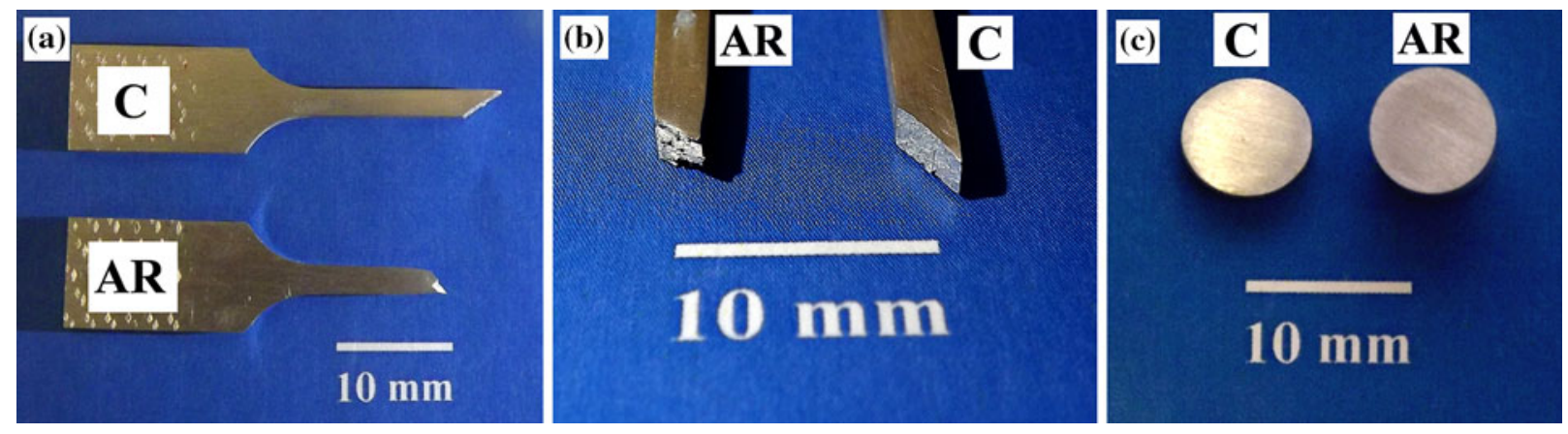

Fig. 5-I-ECAPed (sample C) and the as-received (sample AR) tensile $(a)$ and $(b)$ and the compressive $(c)$ samples after testing. Shear failure is observed in the I-ECAPed tensile sample and flow anisotropy in the I-ECAPed compressive sample.
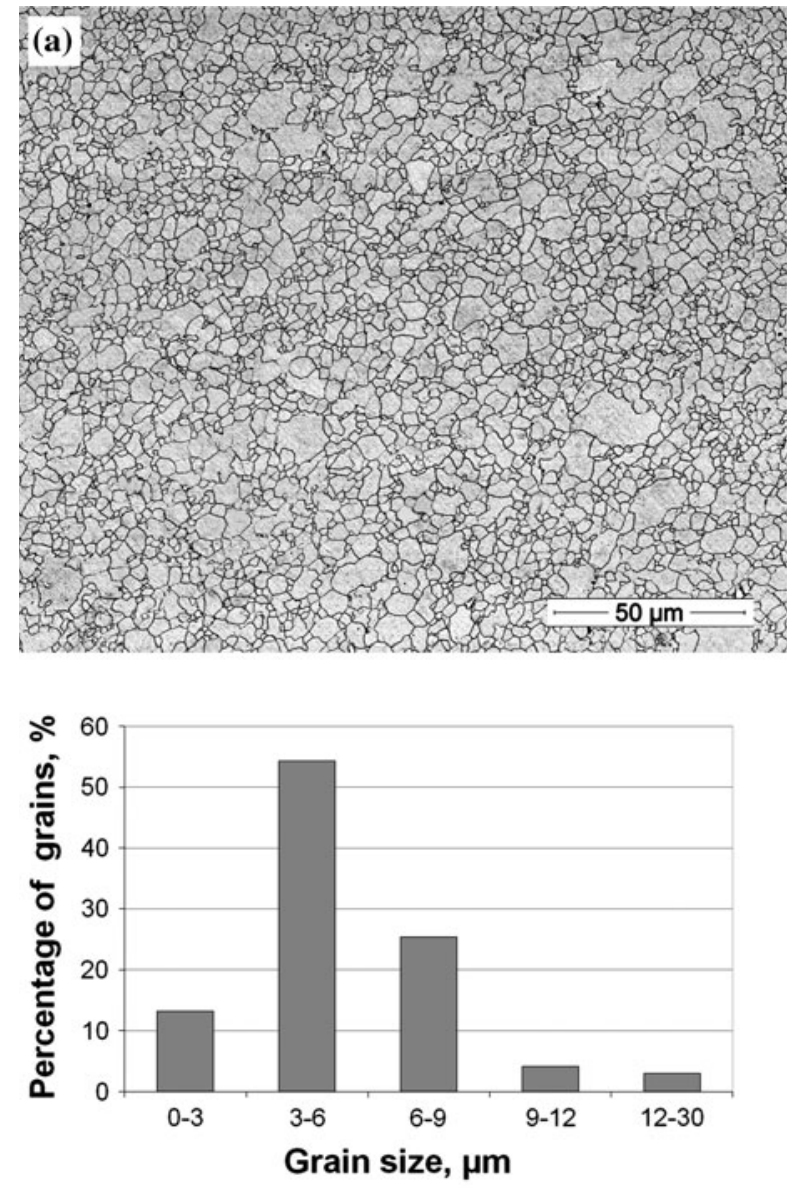

(b)

Fig. 6-SEM microstructural image of the sample processed by route A $(d=5.53 \mu \mathrm{m})$, representative for all samples processed by I-ECAP in the current study $(a)$ and corresponding grain size distribution chart $(b)$.

of the route used. The measured mean grain sizes were very similar for all the three processing routes and were equal to $5.53,5.42$, and $5.37 \mu \mathrm{m}$ for routes $\mathrm{A}, \mathrm{B}_{\mathrm{C}}$, and $\mathrm{C}$, respectively. The effect of the billet rotation between subsequent I-ECAP passes on the microstructural homogenization and grain shape was not observed. The representative microstructural image of the sample
A, with the corresponding grain size distribution chart, is shown in Figure 6. More than 50 pet of grains are within range from 3 to $6 \mu \mathrm{m}$; they are equiaxed grains, most likely arising from DRX taking place at $523 \mathrm{~K}$ $\left(250^{\circ} \mathrm{C}\right)$. Nevertheless, serrated coarse grains, in the as large range as from 20 to $30 \mu \mathrm{m}$, account for 4 pct of all grains. They could be interpreted as unrecrystallized grains observed in the initially extruded sample (Figure 1). Similar grain size and microstructural homogeneity after ECAP processing at $523 \mathrm{~K}\left(250{ }^{\circ} \mathrm{C}\right)$ were reported in Reference 10. Experimental results confirming occurrence of DRX in ECAP of magnesium alloys ware also presented in References 9, 18.

\section{Texture}

Textures of the I-ECAPed samples calculated from EBSD images are shown in Figure 7. The supplied rods were obtained by hot direct extrusion, and it was reported in the past that strong ring fiber texture is formed in this forming operation. ${ }^{[33]}$ Basal planes are aligned almost parallel to ED; the angle between basal plane and extrusion plane is $\sim 5$ deg. Strong basal textures, with intensities in the range from 12 to 16 , were obtained after I-ECAP. The sample A exhibited basal plane inclination of 20 deg with textural intensity being equal to 12 and 13 deg with textural intensity 6 . Grains are orientated more favorably for basal slip in the other two I-ECAPed samples. The inclination angles of basal planes in the samples B and C are 46 and $35 \mathrm{deg}$, respectively. Moreover, the basal planes are inclined at $\sim 45 \mathrm{deg}$ to the transverse direction in the sample B, which is not observed in the sample C. It would result in similar mechanical properties along ED but different flow behaviors when testing along transverse direction (through-thickness).

\section{Microstructures of Deformed Coarse-Grained Samples}

Microstructural images of the sample AR subjected to tension and compression are shown in Figure 8. As seen in Figures 8(a) and (b), almost every coarse grain (bigger than $\sim 50 \mu \mathrm{m}$ ) subjected to tension underwent massive twinning. It is also apparent from those images that some grains are deformed by twins operating on 

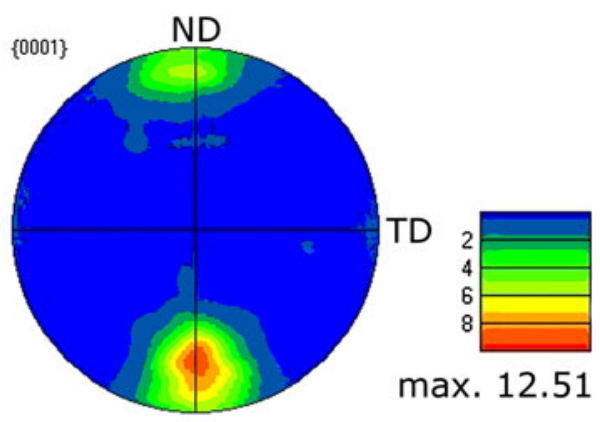

(a)

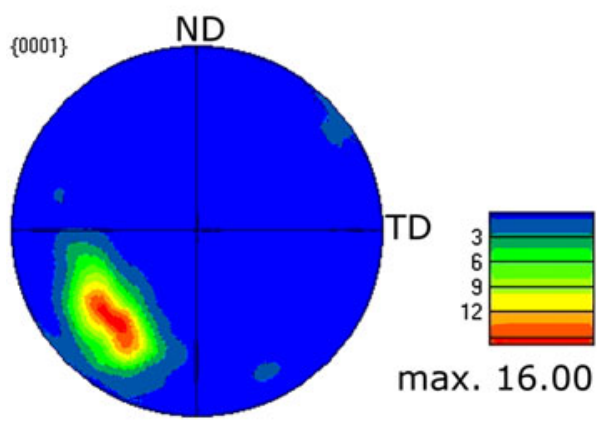

(b)

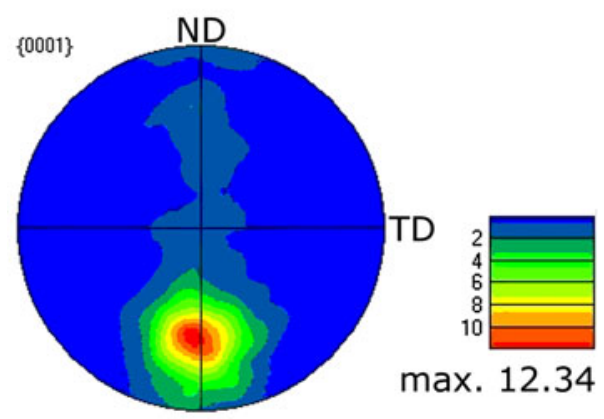

(c)

Fig. 7-(0001) pole figures showing textures after four passes of I-ECAP using routes: $\mathrm{A}(a), \mathrm{B}_{\mathrm{C}}(b)$, and $\mathrm{C}(c)$.

only one plane, whereas there is relatively a large group of grains, in which activities of two and more twinning systems are observed. In Reference 41, EBSD technique was used to show that different $\{10-12\}$ twin variants can operate in the same grain. It is apparent from Figure 8(b) that twins as well as slip lines are hardly observed for grains smaller than $\sim 20 \mu \mathrm{m}$. Similar results were obtained for the samples compressed to strain 0.1 (Figures 8(c) and (d)) where massive twinning in coarse grains, sometimes operating on more than one slip plane, is not accompanied by deformation in smaller grains. Voids or shear bands were not revealed in the tested samples.

\section{E. Microstructures of Deformed Fine-Grained Samples}

As shown in Figure 9, microstructural images of finegrained samples subjected to tension revealed the occurrence of deformation bands in each sample. In the sample A, some bands of extremely deformed grains are parallel to tensile direction (TD) and some inclined at $\sim 45 \mathrm{deg}$ to TD, while in the samples B and C only the latter are observed. For the samples B and C, a large number of twins as well as slip lines are observed within a band. However, dark regions, caused by a larger amount of deformation than in the sample A, make detailed observation more difficult. A small relief on the surface visible in grains outside bands is attributed to a slip-dominated flow. This region is also almost free from twins. The number of shear bands observed in different samples is not the same. The samples B and C exhibit more extensive shear banding than sample A.

Microstructures of the samples subjected to compression are shown in Figure 10. Twins are observed in each sample, irrespective of the route used. However, twinning is more intensive in sample A, compared wit B and C. No relation between grain size and twinning activity was reported in the examined samples. As seen in Figures 10(b) and (c), twins are observed in small $(\sim 5 \mu \mathrm{m})$ and large grains $(\sim 15 \mu \mathrm{m})$. However, large grains without signs of twinning are also revealed. It is shown that twinned grains form small colonies or bands. In the sample A, colonies of twinned grains are bigger that in the samples $\mathrm{B}$ and $\mathrm{C}$ but grains free from twins are also observed. It was not revealed if any "mesoscopic" effects, e.g., shear bands, have arisen from those small colonies/bands. In contrast to the coarse-grained sample, occurrence of only one twin variant in the most of twinned grains is reported.

\section{DISCUSSION}

\section{A. Effects of Grain Size and Texture on Mechanical Properties}

Mechanical properties of hot-extruded AZ31B magnesium rod were significantly changed by I-ECAP. The initial high strength and low ductility of the sample AR can be explained by occurrence of coarse grains and texture produced during extrusion. Basal planes alignment almost parallel to ED resulted in increased yield strength and reduced ductility. Twinning in extruded coarse-grained samples subjected to tension and compression observed in the current study was also reported in Reference 42. It was shown in the same article that twinned coarse-grained samples $(70 \mu \mathrm{m})$ fractured earlier in tension as well as compression than fine-grained $(8 \mu \mathrm{m})$ which did not undergo twinning. Grain refinement resulting in enhancement of ductility is also confirmed in the current article.

Mean grain size obtained after processing by I-ECAP $(-5 \mu \mathrm{m})$ is comparable with results obtained after conventional ECAP at the same temperature ${ }^{[10]}$ Grain refinement led to formability enhancement accompanied by a yield stress decrease, which is usually observed for AZ31 magnesium alloy subjected to ECAP. ${ }^{[17,22]}$ However, results obtained for the sample A indicate that grain size cannot be the only explanation for change of mechanical properties after I-ECAP. Different textural developments, arising from processing route, also contribute to changes in mechanical properties. Results of 

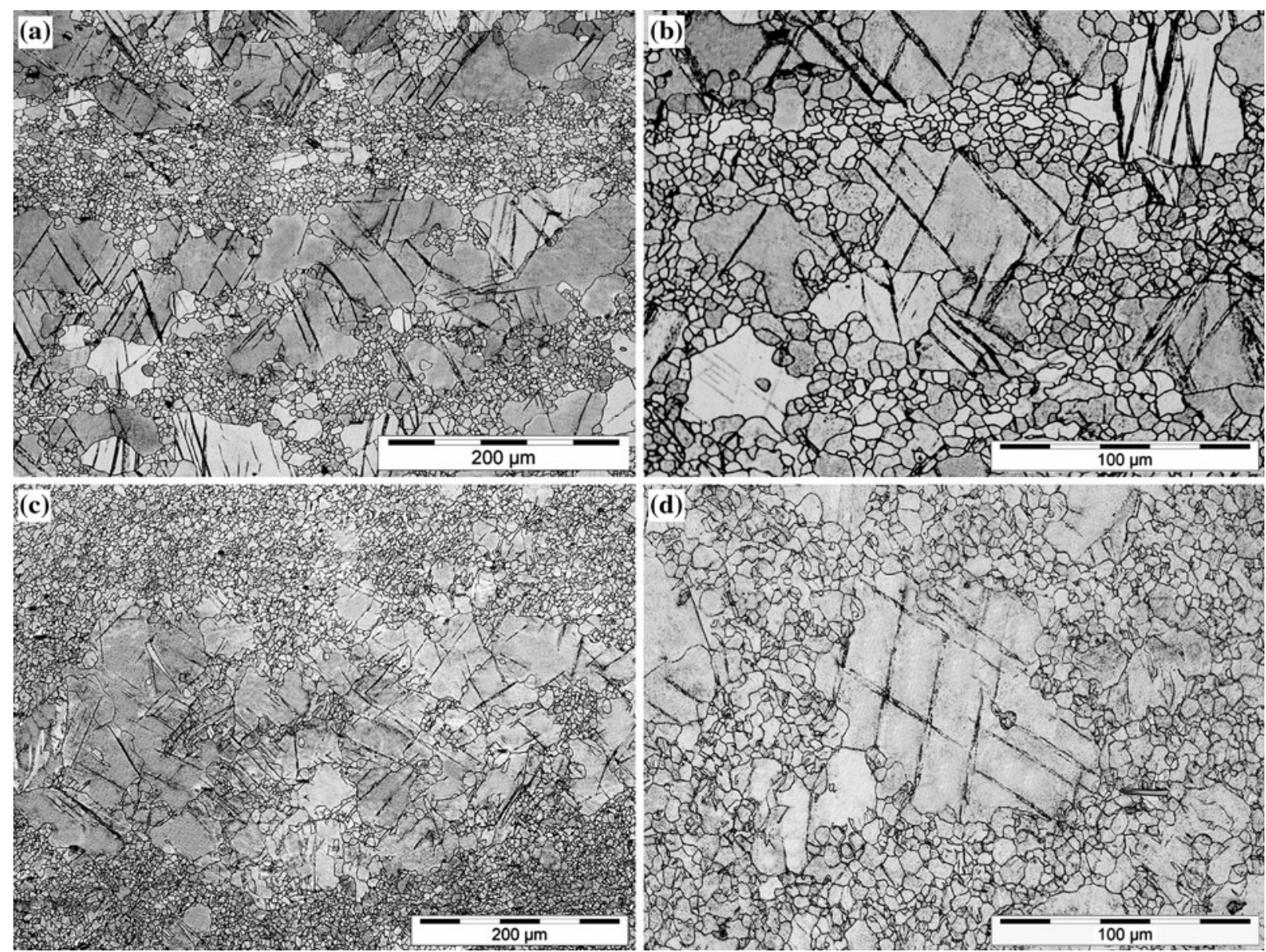

Fig. 8-Microstructural images of the as-received sample subjected to tension $(a)$ and $(b)$ and compression $(c)$ and $(d)$. Zoomed regions $(b)$ and (d) are shown to reveal fine grains free from twinning. Tension direction in (a) and (b) is horizontal.

textural measurements show that slip on basal plane is a favorable mode of deformation in the samples B and C. It explains lower yield stress and enhanced ductility of those samples. In the sample A, basal planes are inclined by 13 to 20 deg to ED which makes slip on basal plane much more difficult. Activation of "harder" deformation mechanisms gives rise to improvement in strength, compared with the samples B and C. However, it was not confirmed that processing by the route A leads to both strength and ductility improvement, as has been shown in Reference 13. This inconsistency can be explained by the fact that samples with different initial textures were used in both studies.

Tension-compression anisotropy of the yield stress observed for the sample AR was almost suppressed for the samples B and C. It can be also explained by textural development in those samples. The measured grain orientations show that hep cells are inclined at $\sim 45 \mathrm{deg}$ to their $c$-axes, their strength in tension and compression are almost the same due to the symmetric alignment of basal planes to both deformation directions. In case of the sample A, basal planes are aligned similar to the extruded sample, and slip on basal plane is limited in compression. Activation of twinning leads to a greater strain hardening and a lower ductility. Distinctive concave shapes of compressive flow stress curves observed for the samples AR and A were also reported for extruded fine-grained samples with grain size $4 \mu \mathrm{m}$ subjected to compression along ED. ${ }^{[36]}$ It clearly shows that grain refinement is not enough to suppress the tension-compression anisotropy, but generation of appropriate texture is also required.

Anisotropic flow was also reported during compression of fine-grained samples. However, it is not clear if the lower yield stress is observed along transverse or normal direction; therefore, this effect needs further investigation. This phenomenon was also studied by conducting a set of compression tests along three different directions of an ECAPed billet. ${ }^{[37]}$ Increased tendency for twinning was observed when sample was tested along throughthickness direction, compared with testing along ED. Textural measurement performed for the sample C shows that basal planes are inclined at $\sim 35 \mathrm{deg}$, which favors basal slip along ED. However, their orientation in through-thickness direction requires activation of different deformation mechanisms. It explains why the largest anisotropy was observed for the sample $\mathrm{C}$, smaller for A and $\mathrm{B}$, and isotropy for the extruded sample. 

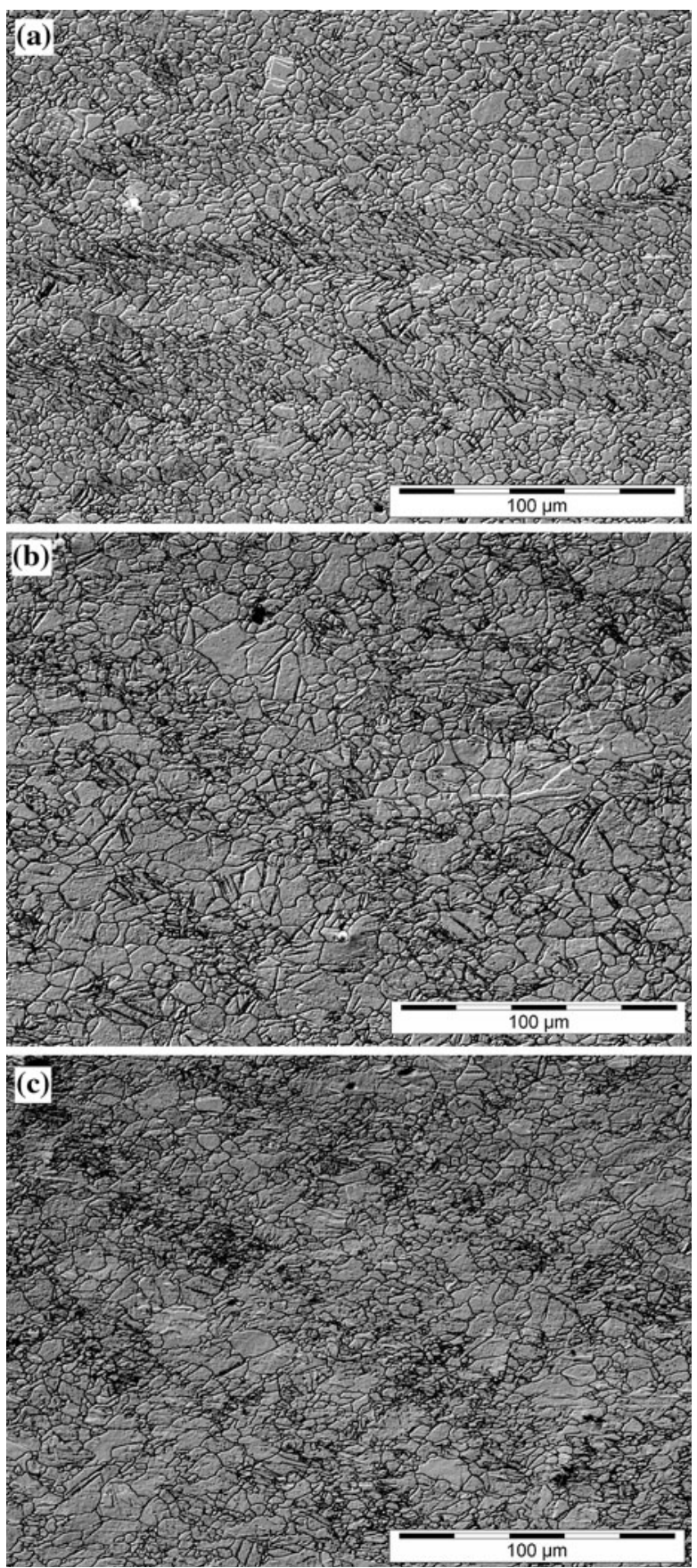

Fig. 9-Microstructural images of fine-grained tensile samples: A (a), $\mathrm{B}(b)$, and C $(c)$ deformed to fracture. Shear bands are revealed in each sample. Tension direction is horizontal.

\section{B. Deformation Mechanisms in Fine-Grained Samples Subjected to Tension}

Deformation bands were revealed in each fine-grained sample subjected to tension. It was difficult to define deformation mechanism operating within a band because of high strain accumulation. However, twins as well as slip lines were identified in the most of grains lying within a band. The mechanism of shear band formation is not clear. Lapovok et al. ${ }^{[43]}$ showed shear band formation in AZ31 subjected to osingle pass of
ECAP at $523 \mathrm{~K}\left(250{ }^{\circ} \mathrm{C}\right)$. Nevertheless, the effect of shear bands on flow behavior during tension was not studied. In the current article, shear bands were not revealed even after four passes of I-ECAP, but they appeared during tensile testing. There is no evidence of any relation between grain size and band formation, because the average grain size within and outside a band is similar. Therefore, observed strain localization was attributed to initial grain orientation.

The mechanism of shear band formation during tension in the I-ECAPed samples is proposed in the current article. It is suggested that grains within a band are deformed by twinning, which was also shown for biaxial tension. ${ }^{[4]}$ However, strong basal texture reported for the samples $\mathrm{B}$ and $\mathrm{C}$ indicate that slip on basal plane is also important deformation mechanism operating both within and outside a band. Lower yield stress of the sample $\mathrm{C}$, compared with sample $\mathrm{B}$, can be attributed to suppression of twinning activity. It is apparent from Figure 9 that more twinned grains are observed in the sample B than in the sample C, which gives rise to the strength improvement of the former one. The quantitative analysis of the twinned area ratio was not possible because of high deformation level.

Texture of the sample A does not favor slip on basal plane; therefore, its ductility is lower compared with other fine-grained samples. Higher strength of the sample A is attributed to greater activity of twinning. The deformation mechanism different from those shown for the samples B and C is illustrated in Figure 11. The following hypothesis is proposed to explain the origin of the observed microstructure: grains are first twinned which causes their reorientation to position which favors basal slip. Twinning behavior resulting in reorientation to basal slip favorable was identified as $\{10-11\}$ $\{10-12\}$ double twinning elsewhere. ${ }^{[4]}$ Since slip on basal plane is much easier to occur than any other deformation mechanism, remarkable strain localization appears. Observed strain localization is probably the main reason for the earlier occurrence of the failure of the sample A, compared with the samples B and C. It should be emphasized that the proposed explanation is only a hypothesis and requires further verification using more sophisticated techniques than optical microscopy.

\section{Deformation Mechanisms in Fine-Grained Samples Subjected to Compression}

Shear failure along diagonal of cylindrical sample observed during compression of coarse- and fine-grained samples could be explained in terms of shear bands formation. It was already shown that strain localization occurs in magnesium samples subjected to compression and leads to earlier failure; this mechanism was described in Reference 41. Initially twinned grains undergo secondary twinning and form double twins. They reorient parent grain to the position which favors slip on basal plane; Schmid factor for basal slip in double-twinned grains was calculated to be $0.5 .^{[45]}$ Moreover, regions previously occupied by double twins are expected to act as sites of void formation since 

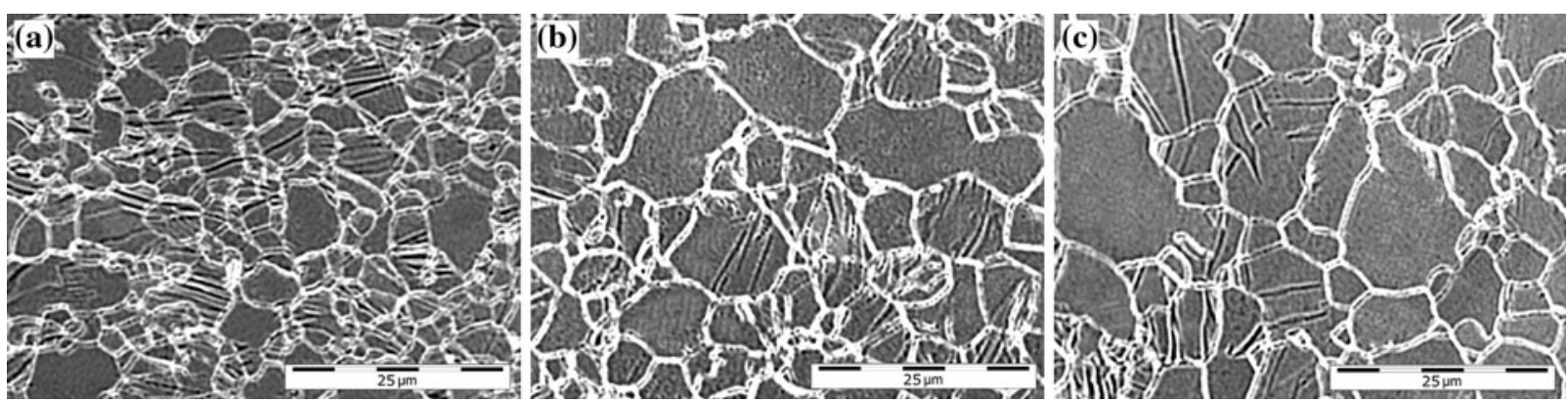

Fig. 10-Microstructural images of the fine-grained samples: A $(a), \mathrm{B}(b)$, and $\mathrm{C}(c)$ compressed to true strain 0.1 . Dark lines are twins revealed in fine grains.
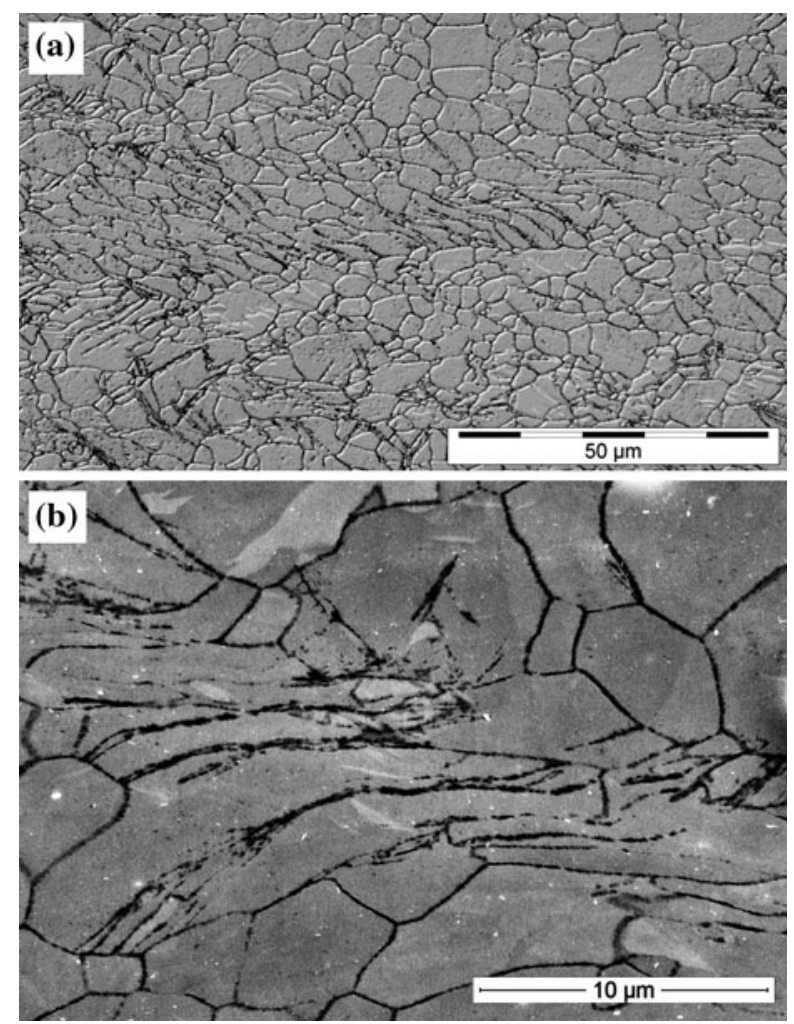

Fig. 11- Shear band observed in tensile sample A deformed to fracture (a) and zoomed region showing twins within deformed grains (b). Tension direction is horizontal.

twin-sized voids were revealed in compressed magnesium sample using the EBSD technique..$^{[41]}$

According to the presented fracture mechanism in compression, suppression of twinning can lead to enhancement of ductility of magnesium alloys. Indeed, grain refinement obtained by I-ECAP resulted in limiting of twinning activity and led to enhancement of ductility in the current study. Due to texture developed during I-ECAP, most of the grains could be deformed by slip on basal plane instead of twinning which delayed the process of double twinning and void formation. It should be noticed that the previous statement is correct when the sample is compressed along ED; there is no experimental evidence in the current study to show that it is also true along other directions.

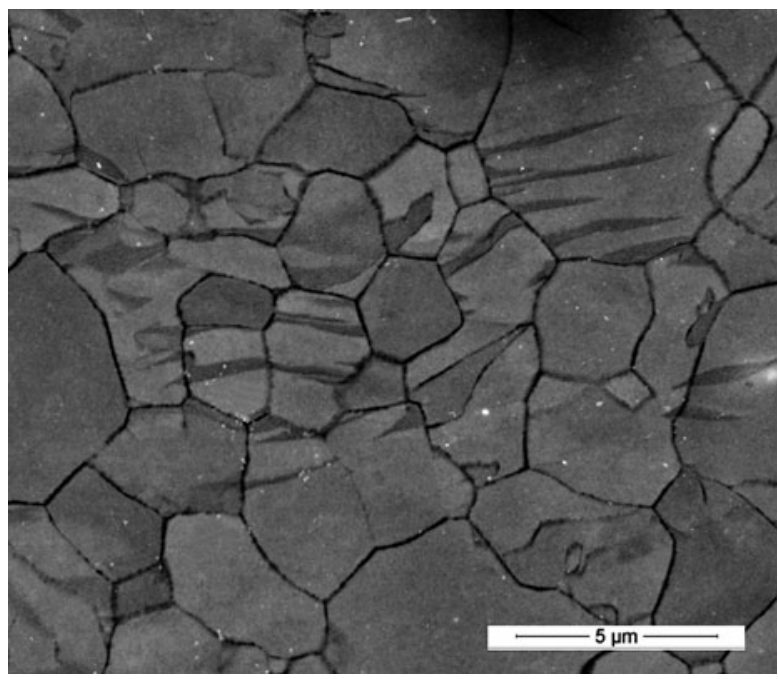

Fig. 12-SEM microstructural image of the sample C compressed to true strain 0.1 . Twins are revealed in very fine grains.

The roles of grain size and its orientation in twin formation are ambiguous. Although grain size is believed to control twinning behavior, ${ }^{[36]}$ twins were observed in grains as small as from 1 to $3 \mu \mathrm{m}$, as shown in Figure 12. Moreover, large grains surrounding twinned regions were completely free from twins. It proves that not only grain size but also grain orientation has strong effect on twinning behavior. Twinned grains are arranged in small colonies which can indicate that not individual grains but whole regions exhibit orientation which favors twinning. It is suggested that, in the current study, those twinned colonies form shear bands where the voids are formed at the subsequent stages of deformation. It would explain why the extensively twinned sample A fractured earlier than the samples B and C. Higher twinning activity in the sample A compared with the samples $\mathrm{B}$ and $\mathrm{C}$ compressed to true strain of 0.1 was confirmed by calculating the total twinned area, and the results are shown in Table I. It is apparent that the twinned area in the sample $\mathrm{A}$ is greater than two times that in the samples B and C. These results are also supported by the distinctive concave shape of the compressive flow stress curve observed for the sample A and not in the cases of the samples B and C, as shown in Figure 3(b). Since the grain size is almost 
Table I. Twinned Area Ratio (Pct) in Samples A, B, and C Compressed to True Strain of 0.1 Along Extrusion Direction

\begin{tabular}{lccc}
\hline Sample & A & B & C \\
\hline Twinned Area Ratio (Pct) & 6.3 & 2.7 & 2.2 \\
\hline
\end{tabular}

the same $(5.45 \pm 0.1 \mu \mathrm{m})$ for each fine-grained sample tested in the current study, the increased twinning activity in the sample A was attributed to the texture produced during I-ECAP.

\section{CONCLUSIONS}

In the current study, AZ31B magnesium alloy was processed for the first time using three different routes of I-ECAP at $523 \mathrm{~K}\left(250{ }^{\circ} \mathrm{C}\right)$. The effect of the route used on mechanical properties was investigated. Microstructures of the coarse- and fine-grained samples subjected to tension and compression were studied using OM and SEM. The following conclusions are drawn from the current study:

1. I-ECAP, a continuous SPD process, can be used to improve the ductility of AZ31B magnesium alloy, and the obtained grain sizes and mechanical properties are comparable with conventional ECAP.

2. Texture controls the mechanical properties of AZ31B magnesium alloy subjected to I-ECAP at $523 \mathrm{~K}$ $\left(250{ }^{\circ} \mathrm{C}\right)$. The results obtained showed that the processing route did not influence its grain size but significantly changed its mechanical properties. The EBSD measurements confirmed the effect of texture on flow behavior of the I-ECAPed magnesium alloy.

3. Tension-compression asymmetry is suppressed by using routes $\mathrm{B}_{\mathrm{C}}$ and $\mathrm{C}$ of I-ECAP in the samples tested along extrusion direction. This effect was also attributed to textural development and microstructural homogenization after processing.

4. Increased ductility after I-ECAP was attributed to suppression of twinning and facilitation of slip on basal plane. Shear bands were observed in the I-ECAPed samples subjected to tension. The larger number of shear bands and smaller spacings between them were observed in samples which exhibited improved ductility.

5. Twinning activity in compression is higher for the samples processed by route $\mathrm{A}$ than by $\mathrm{B}_{\mathrm{C}}$ and $\mathrm{C}$. This conclusion is supported by the concave shape of the flow stress curve and quantitative analysis of microstructural images. Since the average grain size was almost the same for the samples $A, B_{C}$, and $C$, this effect was attributed to the texture produced during different routes of I-ECAP.

\section{ACKNOWLEDGMENTS}

Financial support from the Carpenter Technology Corporation is kindly acknowledged. Part of this research was supported by the Engineering and Physical Sciences Research Council [Grant Number EP/G03477X/1].

\section{REFERENCES}

1. A. Azushima, R. Kopp, A. Korhonen, D.Y. Yang, F. Micari, G.D. Lahoti, P. Groche, J. Yanagimoto, N. Tsuji, A. Rosochowski, and A. Yanagida: CIRP Ann. Manuf. Technol., 2008, vol. 57, pp. 716-35.

2. V.M. Segal: Mater. Sci. Eng. A, 1995, vol. 197, pp. 157-64.

3. Y. Iwahashi, J. Wang, Z. Horita, M. Nemoto, and T.G. Langdon: Scripta Mater., 1996, vol. 35, pp. 143-46.

4. A. Rosochowski and L. Olejnik: Mater. Sci. Forum, 2011, vol. 674, pp. 19-28.

5. L. Olejnik, A. Rosochowski, and M. Richert: Mater. Sci. Forum, 2008, vols. 584-586, pp. 108-13.

6. A. Rosochowski, M. Rosochowska, L. Olejnik, and B. Verlinden: Steel Res. Int., 2010, vol. 81, pp. 470-73.

7. K. Bryla, J. Dutkiewicz, and P. Malczewski: Arch. Comput. Mater. Sci. Eng., 2009, vol. 40, pp. 17-22.

8. L. Jin, D. Lin, D. Mao, X. Zeng, B. Chen, and W. Ding: Mater. Sci. Eng. A, 2006, vol. 423, pp. 247-52.

9. S.X. Ding, C.P. Chang, and P.W. Kao: Metall. Mater. Trans. A, 2009, vol. 40A, pp. 415-25.

10. S. Seipp, M.F.-X. Wagner, K. Hockauf, I. Schneider, L.W. Meyer, and M. Hockauf: Int. J. Plast., 2012, vol. 35, pp. 155-66.

11. M. Gzyl, A. Rosochowski, E. Yakushina, P. Wood, and L. Olejnik: Key Eng. Mater., 2013, vols. 554-557, pp. 876-84.

12. L. Jin, D. Lin, D. Mao, X. Zeng, and W. Ding: Mater. Lett., 2005, vol. 59 , pp. 2267-70.

13. S.X. Ding, W.T. Lee, C.P. Chang, L.W. Chang, and P.W. Kao: Scripta Mater., 2008, vol. 59, pp. 1006-09.

14. S. Biswas, S.S. Dhinwal, and S. Suwas: Acta Mater., 2010, vol. 58, pp. 3247-61.

15. T.G. Langdon: Mater. Sci. Eng. A, 2007, vol. 462, pp. 3-11.

16. R.B. Figueiredo and T.G. Langdon: J. Mater. Sci., 2010, vol. 45, pp. 4827-36.

17. W.J. Kim, C.W. An, Y.S. Kim, and S.I. Hong: Scripta Mater., 2002, vol. 47, pp. 39-44.

18. M. Janecek, M. Popov, M.G. Krieger, R.J. Hellmig, and Y. Estrin: Mater. Sci. Eng. A, 2007, vol. 462, pp. 116-20.

19. A.G. Beer and M.R. Barnett: Metall. Mater. Trans. A, 2007, vol. 38A, pp. 1856-67.

20. S.M. Fatemi-Varzaneh, A. Zarei-Hanzaki, and H. Beladi: Mater. Sci. Eng. A, 2007, vol. 456, pp. 52-57.

21. M. Gzyl, A. Rosochowski, A. Milenin, and L. Olejnik: Comput. Methods Mater. Sci., 2013, vol. 13, pp. 357-63.

22. S.M. Masoudpanah and R. Mahmudi: Mater. Des., 2010, vol. 31, pp. $3512-17$

23. T. Mukai, H. Somekawa, T. Inoue, and A. Singh: Scripta Mater., 2010, vol. 62, pp. 113-16.

24. T. Mukai, M. Yamanoi, H. Watanabe, and K. Higashi: Scripta Mater., 2001, vol. 45, pp. 89-94.

25. S.R. Agnew, J.A. Horton, T.M. Lillo, and D.W. Brown: Scripta Mater., 2004, vol. 50, pp. 377-81.

26. S.R. Agnew, P. Mehrotra, T.M. Lillo, G.M. Stoica, and P.K. Liaw: Mater. Sci. Eng. A, 2005, vol. 408, pp. 72-78.

27. S. Suwas, G. Gottstein, and R. Kumar: Mater. Sci. Eng. A, 2007, vol. 471, pp. 1-14.

28. F. Yoshinaga and R. Horiuchi: Trans. JIM, 1963, vol. 4, pp. 1-8.

29. B.C. Wonsiewicz and W.A. Backofen: Trans. TMS-AIME, 1967, vol. 239 , pp. $1422-31$.

30. M.R. Barnett: Metall. Mater. Trans. A, 2003, vol. 34A, pp. 1799-1806.

31. W.B. Hutchinson and M.R. Barnett: Scripta Mater., 2010, vol. 63, pp. 737-40.

32. T. Al-Samman and G. Gottstein: Mater. Sci. Eng. A, 2010, vol. 527 , pp. $3450-63$.

33. S. Kleiner and P.J. Uggowitzer: Mater. Sci. Eng. A, 2004, vol. 379, pp. $258-63$.

34. R. von Mises: Z. Angew. Math. Mech., 1928, vol. 8, pp. 161-85.

35. J.A. del Valle, F. Carreno, and O.A. Ruano: Acta Mater., 2006, vol. 54 , pp. $4247-59$.

36. M.R. Barnett, Z. Keshavarz, A.G. Beer, and D. Atwell: Acta Mater., 2004, vol. 52, pp. 5093-5103. 
37. R.B. Figueiredo, Z. Szaraz, Z. Trojanova, P. Luka, and T.G. Langdon: Scripta Mater., 2010, vol. 63, pp. 504-07.

38. M. Al-Maharbi, I. Karaman, I.J. Beyerlein, D. Foley, K.T. Hartwig, L.J. Kecskes, and S.N. Mathaudhu: Mater. Sci. Eng. A, 2011, vol. 528, pp. 7616-27.

39. K.U. Kainer, ed.: Magnes.: Proc. 7th Int. Conf. Magnes. Alloys Appl., Wiley-VCH, Frankfurt, 2006, p. 834.

40. E.W. Kelley and W.F. Hosford: Trans. TMS-AIME, 1968, vol. 242 , pp. $5-13$.
41. T. Al-Samman and G. Gottstein: Mater. Sci. Eng. A, 2008, vol. 488, pp. 406-14.

42. Y. Chino, K. Kimura, and M. Mabuchi: Mater. Sci. Eng. A, 2008, vol. 486, pp. 481-88.

43. R. Lapovok, L.S. Toth, A. Molinari, and Y. Estrin: J. Mech. Phys. Solids, 2009, vol. 57, pp. 122-36.

44. J. Scott, M. Miles, D. Fullwood, B. Adams, A. Khosravani, and R.K. Mishra: Metall. Mater. Trans. A, 2013, vol. 44A, pp. 512-16. 45. M.R. Barnett: Mater. Sci. Eng. A, 2007, vol. 464, pp. 8-16. 